\title{
Quality and the Commons: The Surf Gangs of California
}

\author{
Daniel T. Kaffine Colorado School of Mines
}

\begin{abstract}
In open-access settings, high-quality resources are lucrative, yet fencing out potential entrants may be very costly. I examine the endogenous creation of property rights, focusing on the incentives that resource quality provides to close the commons. Analytical examples explore the incentives of locals to increase or decrease the strength of property rights conditional on how locals and nonlocals value the quality of the resource. The empirical analysis looks at a unique resource-surf breaks - and estimates the relationship between the exogenous quality of the resource (waves at the surf break) and local attempts to seize the common surf break. Using cross-sectional data on 86 surf breaks along the southern California coast, this paper finds that a 10 percent increase in quality leads to a 7-17 percent increase in the strength of property rights.
\end{abstract}

\section{Introduction}

Since the publication of Hardin's (1968) seminal work "The Tragedy of the Commons," there has been extensive research and debate regarding the implications of resources without well-defined property rights. If private property rights were put in place over these resources, economically efficient behavior should result (Coase 1960). Some authors (Ostrom 1990; Cole 2002) argue that rules of use have been developed in many common-property resources that allow users to avoid the tragedy of the commons without the need for formal private property. In either case, theory strongly suggests that the presence of property rights (private or commonly enforced) avoids overexploitation and congestion (Scott 1955; Gordon 1954), leading to rent preservation and increased resource quality.

Another line of literature by authors such as Demsetz (1967) argues that property rights will be endogenously created by users when the benefits of developing and enforcing property rights exceed the costs. ${ }^{1}$ These two lines of

The author acknowledges financial support from the National Science Foundation (grant 0114437). This paper was greatly improved by comments from Jonah Busch, Chris Costello, Robert Deacon, Gary Libecap, and John Lynham.

${ }^{1}$ See Umbeck (1981) and Libecap (1989) for studies of the creation of mineral rights in the western United States.

[Journal of Law and Economics, vol. 52 (November 2009)]

(C) 2009 by The University of Chicago. All rights reserved. 0022-2186/2009/5204-0029\$10.00 
thought imply an endogeneity between resource quality and the strength of property rights. If we observe a high-quality fishery with strong property rights, is quality high because strong property rights encourage investment in the resource, or did users recognize the high quality of the resource and move to establish strong property rights?

This paper examines the following questions: How does resource quality influence the strength of informal property rights? Do owners necessarily benefit from an increase in quality? If quality does affect the strength of property rights, what are the implications for empirical studies when resource quality is endogenous to property rights?

This paper builds on the common-property literature by considering the strength of user-enforced informal property rights in an equilibrium setting, where welfare-maximizing locals and open-access nonlocals derive benefits from a resource of exogenous quality but suffer costs either from exerting exclusionary effort or from being on the receiving end of exclusionary effort. Locals are assumed to formally or informally solve the collective action problem and decide how much effort should be expended at their local site to keep out nonlocals. ${ }^{3}$ I use simple analytical examples to show that an increase in quality does not necessarily make locals better off. Because nonlocals are also looking to capture the increased quality, the indirect costs of increased congestion from nonlocals may overwhelm the direct benefits of increased quality. Additional examples show that exogenous quality may increase or decrease the strength of property rights; the direction depends crucially on the relative valuation of quality by locals and nonlocals.

In order to identify causation between quality and property rights, an exogenous measure of quality is required. Unlike frequently studied resources such as fisheries, surf breaks (locations where waves are particularly conducive to surfing) have the feature that wave quality is exogenous with respect to property rights. ${ }^{4}$ The complex combination of tides, geology, and climatology that lead to high-quality waves would remain unchanged, even under private ownership. Waves do not care if they are ridden or not, which removes the feedback effects between the biophysical and social systems that are present in fisheries, for example. This natural exogeneity isolates the effect of quality in the estimation of its impact on property rights.

\footnotetext{
${ }^{2}$ For example, when users can invest in a resource, such as replanting of trees or low-impact harvesting techniques.

${ }^{3}$ Common-property attempts to close the commons need not be formal. Acheson (1988) describes the informal system of "territorialism" that dominates the harbor lobster fisheries of coastal Maine. The local lobstermen in each small fishing community effectively exclude all outside lobstermen from fishing in their harbors. The methods employed to exclude nonlocals run from the rather discrete (soft social pressure) to the less subtle (cutting of lobster traps that do not belong to the local harbor) to the decidedly unsubtle burning of boats and physical threats. Attempts by local surfers to close the commons follow a very similar pattern. Nazer (2004) also notes the similarity between surfers and the lobstermen that Acheson describes.

${ }^{4}$ Rider (1998) is the only other paper I am aware of that explicitly models surfing behavior in an economic framework.
} 
I use a unique cross-sectional data set covering 86 surf breaks along the California coast from San Diego to Big Sur to estimate the impact of exogenous wave quality on the strength of informal property rights. In the surfing context, groups of users known as "locals" enforce informal property rights, or localism, in order to reduce congestion from potential entrants, who are denoted "nonlocals." While not recognized legally, user-enforced informal property rights such as localism have features similar to those of formal property rights, such as rules on who may and may not have access to the resource. ("Localism" and "property rights" are used interchangeably throughout this paper.) Surfers in many locations (including California) will tell visitors which breaks are open to anyone and which ones to steer clear of because of localism.

The regression analysis finds a significant positive correlation between exogenous wave quality and localism, such that a 10 percent increase in quality is associated with a 13 percent increase in localism. This suggests that the gains from exclusive access to more valuable resources outweigh the exclusionary cost. Thus, per Demsetz, the gains of creating property rights outweigh the costs of enforcing them, and we observe stronger property rights over better surfing sites. Thus, studies that attempt to infer the impact of property rights on quality must exercise caution in empirically attributing high resource quality to stronger property rights. The impact of property rights on resource quality may be overstated if the underlying differences in quality are not controlled for.

\section{Surfing and Localism in California}

Surfing in California has typically been associated in the popular zeitgeist with the image of laid-back surfer dudes and dudettes hangin' ten and soaking up the warm sun. But surfing in California has a less pleasant side: localism. Even though the law defines the coast as open access up to the high-tide mark, surfers at many breaks enforce informal property rights known as localism. ${ }^{5}$ It has been noted that many longtime surfers feel that they own a break after surfing it for years and display varying degrees of hostility to nonlocals who try to surf their prized spots. This pattern of behavior has been observed in other open-access resources as well. ${ }^{6}$ In the surfing context, hostility toward nonlocals often takes the form of aggressive maneuvers on the waves, verbal abuse, or even physical confrontation.

Surfline.com's Surfology Glossary defines "locals" as "[1]ong time regulars at a particular surf spot or area. Locals may or may not live at or near the spot,

\footnotetext{
${ }^{5}$ Outside the United States, there are some examples of formal property rights systems over surf breaks, predominately in the South Pacific. These exclusive surf resorts include Nihiwatu, Indonesia, and Tavarua, Fiji, where surfers can enjoy world-class, congestion-free waves for a healthy price. For example, in Tavarua, a deal was struck in the early 1980s between Dave Clark and the local Fijian chief, Druku, that allowed Clark to build an exclusive resort on the island in exchange for future revenues. Despite this deal, the legal rights to the famed Cloudbreak were not resolved until 1996 (Borden 2005).

${ }^{6}$ Acheson (1988) provides vivid examples of such behavior by Maine lobstermen.
} 
but their regular surfing means they are accepted as particularly knowledgeable or experienced by the local surfing community. Locals can be very protective of their surf spot and outsiders need to be very aware to the fact that they are visitors." 7 The process of becoming a local varies from break to break but typically involves regularly surfing a site and showing deference (paying one's dues) to the established locals. ${ }^{8}$

While localism may run counter to the common perception of surfers, it is a phenomenon that makes a great deal of economic sense. The finite number of waves per hour implies that surf breaks are a congestible resource. In response, both localism and rules of etiquette have emerged to deal with congestion. ${ }^{9}$ Etiquette helps users determine who gets to ride which wave at a site (reducing collisions and increasing everyone's benefit), while localism is a method for rationing who gets to surf where.

Oftentimes, surf breaks have well-defined zones in which waves routinely break, which leads to an informal lineup of surfers in the water taking turns catching waves. While dropping in front or behind another surfer after they have claimed a wave is typically a gross breach of etiquette, those techniques may also be used by locals to intimidate or just ruin the day of nonlocals. Off the waves, localism at its worst can take the form of broken surfboard fins, slashed tires, broken windows, or even physical violence. ${ }^{10}$

Despite the opposition that nonlocals may face, the brave and daring are willing to take a chance if the waves are particularly good. Along the Santa Barbara County coast, a collection of breaks known as "the Ranch" is famous for its world-class waves and its first-rate localism. The undeveloped coastline was purchased for a healthy sum by landowners who do not allow public access by land to the breaks. Nonetheless, enterprizing surfers frequently launch boats from Point Conception and Gaviota and motor or paddle up the coast and moor offshore. Surfline.com warns, "First timers boating or, arms willing, kayaking in, will almost certainly be met with scowls and frowns of disapproval, if not outright shouting and physical hostility" (Heller 2000).

But localism does have some benefits. Surfing can be a dangerous activity, and the fact that locals have knowledge of various hazards at a given site may decrease the risk of injury to themselves and other surfers. Furthermore, intense local knowledge can lead to better surfing. Professional surfer Nick Carroll spent a week trying to surf the most localized breaks in southern California and observed, "[A local] paddles way outside to where the sets are trying and failing

\footnotetext{
${ }^{7}$ Surfline/Wavetrak, Surf Glossary A-Z (http://www.surfline.com/surfology/surfology_glossary _index.cfm).

${ }^{8}$ See Nazer (2004) for more details on the local norms of surfers. While beyond the scope of this paper, an exploration of the determinants of local status and the size of the local gang may prove enlightening.

${ }^{9}$ See Rider (1998) for a game-theoretic take on the evolution of etiquette and norms in surfing.

${ }^{10}$ A former neighbor and professional surfer recalls a trip with his father during which their car's tires were popped by spike strips thrown by locals. Their transgression: bringing longboards to a shortboards-only site, immediately identifying themselves as nonlocals.
} 
to break. You're kidding, matey, I think, but then, after a minute of waiting, the guy catches a wave from where nobody's managed all surf. Then he pulls three more in a row and actually gets a barrel. Localism's good side-a surfer of normal ability, raised to something higher through knowledge of his spot" (Carroll 2005).

In Section 3, an analytical model captures the general features of this dynamic in which locals decide on the intensity of their exclusionary efforts toward nonlocals, taking into account the quality of the resource.

\section{Locals, Nonlocals, and the Commons}

This section analytically describes local attempts to close the commons. The potential population of users is separated into two groups, locals and nonlocals. ${ }^{11}$ Both locals and nonlocals are assumed to have perfect information about the resource site. Simple examples consider the equilibrium strength of property rights when an exogenous local population exerts exclusionary effort against an endogenous nonlocal population with an open-access reservation utility.

\subsection{User-Enforced Property Rights}

Consider a fixed number of identical locals $\bar{n}_{\mathrm{L}}$ maximizing their return from a resource of exogenous quality by collectively determining a level of exclusionary effort, or localism, $y$, to apply to nonlocals: ${ }^{12}$

$$
\max _{y} U_{\mathrm{L}}\left(q, n_{\mathrm{NL}}\right)-c(y),
$$

where $U_{\mathrm{L}}$ describes the utility locals receive from a resource of exogenous quality $q$ with congestion from an expected number of nonlocals $n_{\mathrm{NL}}{ }^{13}$ It is costly for locals to expend effort to keep out nonlocals, represented by $c(y)$, which is increasing $\left(c^{\prime}(y)>0\right.$ and $\left.c^{\prime \prime}(y)>0\right)$ in the level of localism $y$. Assume that benefits of the resource increase with quality $\left(\partial U_{\mathrm{L}} / \partial q>0\right)$, benefits decrease with congestion $\left(\partial U_{\mathrm{L}} / \partial n_{\mathrm{NL}}<0\right)$, and the marginal benefit of resource quality is decreasing with congestion $\left(\partial^{2} U_{\mathrm{L}} / \partial q \partial n_{\mathrm{NL}}<0\right)$. This utility function assumes that the exogenous number of locals $\bar{n}_{\mathrm{L}}$ has no influence on their own utility; thus, the

${ }^{11}$ Rider (1998) employs a game-theory model with a similar distinction between locals and highway surfers (nonlocals). The author argues that a locals-only policy may be a rational response to congestion pressure from highway surfers.

${ }^{12}$ I (heroically) ignore the problem of collective action on the part of the locals and assume that they can specify a collective level of localism that members will assert. Given the homogeneity assumption and the fact that locals tend to have other social mechanisms enforcing cooperation (Ellickson 1986), the assumption becomes less heroic.

${ }^{13}$ This exogeneity assumption is crucial. If resource quality is not exogenous, feedback between the strength of property rights and quality would need to be considered as well. Treating quality as exogenous isolates the incentives locals have to close the commons. Incorporating investments in resource quality as a function of exclusionary effort (localism) would be an interesting extension but is beyond the scope of this paper. 
optimization above can be thought of as a second-stage decision after locals have worked out the first-stage collective action problem.

Nonlocals, on the other hand, are assumed to be large in number and will come to the resource site as long as the value of using that site meets or exceeds their next-best alternative. Thus, the resource has infinite congestion pressure from the area at large, and all nonlocals receive utility $\bar{V}$ under open access. Therefore, the nonlocal utility function is given as

$$
U_{\mathrm{NL}}\left(q, n_{\mathrm{NL}}\right)-p(y)=\bar{V},
$$

where $U_{\mathrm{NL}}$ describes the benefit nonlocals receive from a resource of quality $q$ with congestion from other nonlocals $n_{\mathrm{NL}}$ and $p(y)$ is the increasing punishment of localism $y$ at the resource site. The assumptions on $U_{\mathrm{NL}}$ are the same as those on $U_{\mathrm{L}}\left(\partial U_{\mathrm{NL}} / \partial q>0, \partial U_{\mathrm{NL}} / \partial n_{\mathrm{NL}}<0\right.$, and $\left.\partial^{2} U_{\mathrm{NL}} / \partial q \partial n_{\mathrm{NL}}<0\right)$.

Equation (2) thus implicitly defines the expected number of nonlocals as a function of quality, localism, and reservation utility as

$$
n_{\mathrm{NL}}=n(q, y, \bar{V}),
$$

which is increasing in $q$, decreasing in $y$, and decreasing in $\bar{V}$. This is intuitive because a higher quality resource will have more people interested in using that resource, stronger property rights will deter more people from using that resource, and fewer people will be interested in using a resource if better returns can be had elsewhere.

Given equations (1)-(3), what level of localism $y$ should locals choose, and will it be increasing or decreasing in quality?

\subsection{Closing the Commons}

Equation (3) implicitly defined the number of nonlocals who would harvest at a resource site given quality $q$, localism $y$, and reservation utility $\bar{V}$. When locals decide $y$, they will choose a level of exclusionary effort with the knowledge that they can exclude some of the nonlocals by making it more costly to use the site. Thus, substituting equation (3) into the optimization problem gives

$$
\max _{y} U_{\mathrm{L}}[q, n(q, y, \bar{V})]-c(y),
$$

which will be solved by some optimal level of localism $y^{\star} \geq 0$. Because I am interested in the effect of resource quality on the strength of property rights, I would like to know how the optimal strength of property rights changes with respect to quality, or $\partial y^{\star} / \partial q$. An increase in quality would give locals more benefit to capture, but it will also increase the number of expected nonlocals at the site, indirectly decreasing the benefits for locals.

While the effect of quality on the strength of property rights may be difficult to predict, it seems logical that an increase in quality should at least make locals better off. However, it is ambiguous whether an increase in quality is actually beneficial to locals. While the direct benefits are certainly positive, they may be 
offset by the onrushing hordes of nonlocals who also want to use the higher quality resource.

Let the value function for locals be given by

$$
V=\max _{y} U_{\mathrm{L}}[q, n(q, y, \bar{V})]-c(y) .
$$

The change in locals' value function due to a change in quality, $\partial V / \partial q$, is then given by

$$
\frac{\partial V}{\partial q}=\frac{\partial U_{\mathrm{L}}}{\partial q}-\frac{\left(\partial U_{\mathrm{L}} / \partial n\right)}{\left(\partial U_{\mathrm{NL}} / \partial n\right)} \frac{\partial U_{\mathrm{NL}}}{\partial q}
$$

and may be positive, negative, or equal to zero. ${ }^{14}$ The first term represents the direct benefits that locals receive from the resource, and the second term represents the indirect congestion costs due to an increase in nonlocals.

This tension between the direct quality and the indirect congestion effects also plays a significant role in determining the relationship between quality and the strength of informal property rights. This relationship is explored in the following examples.

\subsection{Analytical Examples}

As shown above, a change in quality has two competing effects: locals receive some direct benefit but face an indirect cost from an increase in nonlocals. How this tension plays out in terms of a change in the strength of informal property rights is explored in the following three cases. ${ }^{15}$

\subsubsection{Locals and Nonlocals Derive Constant Benefits from Increasing Quality}

When would we expect an increase in quality to have no effect on the strength of property rights? Intuition suggests that if the direct and indirect effects of quality and congestion in equation (6) cancel each other out, the net effect on locals' incentives to create stronger property rights would be zero.

Suppose that local and nonlocal utility functions are linear transforms of each other and equations (1) and (2) take the form

$$
\max _{y} \frac{B_{\mathrm{L}} q}{n}-c y^{2}
$$

\footnotetext{
${ }^{14}$ By the envelope theorem, the impact of quality on the choice of localism can be ignored. Thus, $\partial V / \partial q=\partial U_{\mathrm{L}} / \partial q+\left(\partial U_{\mathrm{L}} / \partial n\right)(\partial n / \partial q)$. By the implicit-function theorem (see theorem 4.17 in Sydsaeter, Strom, and Berck 1999), $\partial n / \partial q=-\left(\partial U_{\mathrm{NL}} / \partial q\right) /\left(\partial U_{\mathrm{NL}} / \partial n\right)$, and that substitution gives equation (6). To confirm that $\partial V / \partial q$ may take any sign, recall the assumptions regarding the shape of $U_{\mathrm{L}}$ and $U_{\mathrm{NL}}$ with respect to quality and congestion.

${ }^{15}$ Let $q$ and $n$ be defined on $(1, \infty)$ for the following examples.
} 
and

$$
\frac{B_{\mathrm{NL}} q}{n}-p y=\bar{V}
$$

where $B_{\mathrm{L}}$ and $B_{\mathrm{NL}}$ represent valuation parameters for locals and nonlocals and $p$ and $c$ represent cost parameters associated with the punishment from and the exertion of localism. Rearranging for $n$,

$$
n=\frac{B_{\mathrm{NL}} q}{\bar{V}+p y}
$$

and inserting into the locals' optimization problem and solving for $y^{\star}$ yields

$$
y^{*}=\frac{B_{\mathrm{L}} p}{2 B_{\mathrm{NL}} c},
$$

which is independent of quality $q$; thus, $\partial y^{*} / \partial q=0$.

Under this case, even if locals derive more benefit per unit of quality $\left(B_{\mathrm{L}}>\right.$ $B_{\mathrm{NL}}$ ), there is no incentive to increase localism. But when might the impact of quality on the strength of property rights be nonzero?

\subsubsection{Locals (Nonlocals) Derive Convex (Constant) Benefits from Increasing Quality}

Intuitively, if the direct effect of increased quality outweighs the indirect effect of increased congestion, locals will increase their protection of the resource. Suppose that locals receive an increasing benefit from increased resource quality, such that an additional bit of congestion is very harmful for locals. When the quality increase leads to more entry by nonlocals, an incentive is created for locals to increase their exclusionary efforts to avoid the large negative utility from increased congestion, and $\partial y^{\star} / \partial q>0$.

In this case, congestion disutility affects locals worse than nonlocals, such that $\partial U_{\mathrm{L}} / \partial n<\partial U_{\mathrm{NL}} / \partial n$ and $\partial^{2} U_{\mathrm{L}} / \partial q \partial n<\partial^{2} U_{\mathrm{NL}} / \partial q \partial n$, where equations (1) and (2) take the form

$$
\max _{y} \frac{B_{\mathrm{L}} q^{2}}{n}-c y^{2}
$$

and

$$
\frac{B_{\mathrm{NL}} q}{n}-p y=\bar{V}
$$

Note that quality now enters locals' utility as a convex, quadratic term. Re- 
arranging for $n$ yields equation (9). Inserting into the locals' optimization problem and solving for $y^{\star}$ yields

$$
y^{*}=q \frac{B_{\mathrm{L}} p}{2 B_{\mathrm{NL}} c},
$$

which depends positively on quality $q$; thus, $\partial y^{\star} / \partial q>0$.

It is plausible that local and nonlocal users might derive different benefits from resources of different quality (for example, because of better information or locals' specialized techniques). In this case, the increasing benefits for locals relative to nonlocals provide an incentive to increase localism.

\subsubsection{Locals (Nonlocals) Derive Concave (Constant) Benefits from Increasing Quality}

At the same time, if nonlocals derive greater benefits from higher quality resources and are more costly to eject, an incentive is created to decrease the strength of property rights, as it is relatively more costly for locals to push out nonlocals.

Suppose that local and nonlocal utility functions take a form in which congestion disutility affects nonlocals worse than locals, such that $\partial U_{\mathrm{L}} / \partial n>$ $\partial U_{\mathrm{NL}} / \partial n$ and $\partial^{2} U_{\mathrm{L}} / \partial q \partial n>\partial^{2} U_{\mathrm{NL}} / \partial q \partial n$, where equations (1) and (2) take the form

$$
\max _{y} \frac{B_{\mathrm{L}} \sqrt{q}}{n}-c y^{2}
$$

and

$$
\frac{B_{\mathrm{NL}} q}{n}-p y=\bar{V} .
$$

In this case, the square root of quality now enters locals' utility. Rearranging for $n$ yields equation (9). Inserting into the locals' optimization problem and solving for $y^{\star}$ yields

$$
y^{\star}=\frac{1}{\sqrt{q}} \frac{B_{L} p}{2 B_{N L} c},
$$

which decreases when quality $q$ increases; thus, $\partial y^{\star} / \partial q<0$.

The case presented above may represent a situation in which nonlocals gain a greater benefit from increasing quality relative to locals, for example, in a developing country in which nonlocals may possess a technological or market advantage in exploiting a resource. In this case, the decreasing benefits for locals relative to nonlocals provide an incentive to decrease localism.

Because the empirical model estimates localism $y$, the above equations allow me to discuss the impact of various parameters on equilibrium localism. Equations (10), (13), and (16) share a common term, $B_{\mathrm{L}} p / 2 B_{\mathrm{NL}} \mathcal{C}$, which shows that 
increasing the valuation parameter for locals, $B_{\mathrm{L}}$, leads to more localism. ${ }^{16}$ Conversely, an increase in the valuation parameter for nonlocals, $B_{\mathrm{NL}}$, leads to less localism. An increase in the effectiveness of punishment, $p$, leads to more localism, while an increase in the cost of enforcing property rights, $c$, leads to less localism. ${ }^{17}$

These examples point to the importance of the relative shape of locals' and nonlocals' utility functions in determining the response of localism to quality. Thus, in environments with many heterogeneous agents potentially using a resource, the endogeneity between the quality of the resource and the strength of property rights may pose a greater empirical concern when assessing the impact of property rights on investments in resource quality.

In order to isolate the response of the strength of property rights to resource quality, a resource is needed whose quality is exogenous to property rights. In the next section, a resource with exogenous quality is examined: surf breaks in southern California. Using data on these surf breaks, I estimate how localism varies with quality, $\partial y^{\star} / \partial q$.

\section{Empirical Model}

\subsection{Data on Surf Breaks}

The primary variable of interest is localism at different surf breaks ( localism $_{i}$ ), however, the strength of informal property rights can be a difficult variable to quantify. Fortunately, the surfing resource Web site Surfline.com reports crosssectional data for 86 surf breaks from Big Sur in central California to Imperial Beach near the California-Mexico border, giving an indexed level of localism from 0 to 10. The data are in the form of a travel report for each break written by surfers with extensive absolute and relative knowledge of the breaks in the area. While the cardinality of the index and its subjective nature may raise some red flags, it provides a consistent assessment of the level of localism as viewed by those who use the resource. ${ }^{18}$

The primary explanatory variable of interest is the quality of the waves at each break. Wave quality is indexed $1-10$ by Surfline.com in the same crosssectional data. According to the site, a score of 1 corresponds to Lake Erie, while a score of 10 corresponds to the famed perfect waves at Jeffreys Bay in South Africa. Data on the congestion (congestion ${ }_{i}$ ) at the break, dirtiness of the break

\footnotetext{
${ }^{16}$ Perhaps because locals have more experience or knowledge of how to best use their local resource. Anyone who has fished an unfamiliar lake with a local angler can attest to the value of knowing which lure to use where and at what time.

${ }^{17}$ In systems of informal property rights like the one described here, exertion of exclusionary effort is done in lieu of formal government policing. Costs of enforcing informal property rights may increase if, for example, government bodies crack down on nonstate enforcement of property rights (Ostrom 1990).

${ }^{18}$ See Surfline/Wavetrak, Travel (http://www.surfline.com/travel) for data on surf breaks around the world. In order to minimize unobservable variations across regions, I focus on central and southern California. I collected the data in 2004.
} 
Table 1

Summary Statistics

\begin{tabular}{lcccr}
\hline Variable & Mean & SD & Min & Max \\
\hline Quality & 5.72 & 2.037 & 2 & 10 \\
Congestion & 4.84 & 2.614 & 0 & 10 \\
Localism & 3.93 & 2.942 & 0 & 10 \\
Dirty & 3.75 & 2.285 & 1 & 10 \\
Work & 4.76 & 1.568 & 1 & 9 \\
Hwydist (miles) & 8.80 & 10.981 & 0 & 55 \\
Ability & 2.24 & .607 & 1 & 4 \\
Popdens (persons $/ \mathrm{km}^{2}$ ) & 496 & 506 & 29 & 1,392 \\
\hline
\end{tabular}

$\left(\right.$ dirty $\left._{i}\right)$, and the paddling difficulty ( work $_{i}$ ) are indexed 1-10 in the same Surfline.com data. Those same data also give recommended ability levels (ability ${ }_{i}$ ) for each break, indexed 1-4, with 1 being a beginner's break, 2 for intermediate surfers, 3 for more advanced surfers, and 4 for experts only.

The remoteness of different breaks may affect both congestion and localism. Surfers who drive to more isolated locales face greater transportation costs, and at the same time, locals who mete out punishment to nonlocals are less likely to incur the wrath of local law enforcement. I used Mapquest to calculate data on highway distance (hwydist ${ }_{i}$ ) from the major city (population greater than $50,000)$ nearest to the break. ${ }^{19}$ In addition, I obtained population density for each county (popdens $s_{i}$ ) from the 2000 U.S. Census.

Table 1 provides summary statistics for the observed data. Each of the six index variables have been averaged over the 86 breaks and have means relatively close to the midrange of the observed values, with the average recommended ability falling between the intermediate and advanced levels. The minimumdistance observations represent breaks in the downtowns of major cities, while the maximum-distance observations represent breaks in the more remote central coast. Minimum population density corresponds to San Luis Obispo County, and the maximum corresponds to Orange County.

\subsection{Data Challenges}

There are several issues that arise in using these data. First, there may be some concern that the quality measure provided by Surfline.com may incorporate other characteristics of the break (such as paddling difficulty and cleanliness). However, the fact that quality has been separately categorized on the Surfline.com Perfect-O-Meter with bounds corresponding to a horrible wave site (Lake Erie) and a great site (Jeffreys Bay) suggests that the quality variable is solely based on wave quality. Other attributes such as congestion, localism, dirtiness, current strength, and even shark danger are given their own indexes and descriptive bounds.

${ }^{19}$ Mapquest's (http://www.mapquest.com) Driving Directions feature gives highway distances in miles between two points. 
Second, there is legitimate concern regarding the nature of these subjective indexes. While they are an attempt by the users of the resource in question to capture the impact of these attributes, there is a chance that a writer may attempt to protect his favorite spot by underreporting the quality of the waves and overreporting the level of localism or some other negative attribute. It should be noted that at the end of every travel report, readers are encouraged to e-mail Surfline.com if the report is found lacking. Furthermore, as the most comprehensive surf site on the Web, Surfline.com has a strong incentive to provide accurate information to the more than 1,000,000 monthly visitors (and the advertising revenue they bring). ${ }^{20}$

Another difficulty arises from the textual description for some entries. For example, at Lunada Bay, a notorious den of localism in south Los Angeles County and the site of an assault on a TV news crew, localism is described as "open arms (nuclear)," which has been interpreted as a 10. While this introduces additional measurement error, I have been as consistent as possible in coding text entries using other descriptions associated with the site. Finally, entries are occasionally given as a range of values-for example, Campus Point near Santa Barbara has a Perfect-O-Meter score of 5-7. I have chosen to use the mean value for the estimations reported below. ${ }^{21}$

\subsection{Estimation Strategy}

Using the cross-sectional data on the 86 surf breaks, I estimate the link between exogenous wave quality and the strength of property rights. The dependent variable, $\operatorname{localism}_{i}$, represents the strength of property rights at break $i$. The primary regressor of interest is quality, and the model is controlled for congestion, the dirtiness of the break, paddling difficulty, and highway distance to the nearest major city. The basic estimation equation is as follows:

$$
\operatorname{localism}_{i}=\alpha+\beta_{1} \text { quality }_{i}+\beta_{2} \text { congestion }_{i}+\delta \boldsymbol{X}_{i}+\varepsilon_{i},
$$

where $\boldsymbol{X}_{i}$ represents the other control variables. The primary interest is in the coefficient $\beta_{1}$, which represents the impact of exogenous wave quality on localism. Per the analytical model, a positive result would suggest that locals derive greater benefits from increasing quality, while a negative result would suggest that nonlocals stand to benefit more from increased quality. A null result would indicate that both groups benefit in a similar fashion from increases in quality, which leads to no change in localism.

${ }^{20} \mathrm{I}$ showed the indexed scores for each site to several semiprofessional surfer acquaintances, who considered the indexes accurate. The sites with the best waves were reported as such, as were the sites with the fiercest localism.

${ }^{21}$ I ran additional regressions using the minimum or maximum reported scores, with little impact on the estimations. 


\section{Surfometrics}

This section presents results from the empirical test of the localism model. Table 2 gives the estimates for changes in localism against quality and other control variables. In the basic regression, localism is positively correlated with quality such that a 10 percent increase in quality leads to approximately a 13 percent increase in localism. This result is statistically robust to all but one alternate specification, with estimates for a 10 percent increase in quality ranging from around 7 percent to 17 percent. Approximately 50 percent of the variance in localism is explained by the model regressors in all specifications.

\subsection{Estimating Localism}

In column 1 in Table 2, the point estimate is large and highly significant, indicating that localism increases by 13 percent because of a 10 percent increase in wave quality. This suggests that the breaks with the best waves are also the breaks that tend to have the strongest enforcement of localism, and thus the gains to locals of closing the commons around high-quality waves outweigh the extra cost associated with enforcement.

Congestion is also positive and correlated with localism, and the likely endogeneity between the two variables is an issue addressed below. The dirtiness of the break and highway distance to the nearest city are positively correlated with localism but statistically insignificant. Paddling difficulty (Work) is negatively correlated with localism and statistically significant at the 10 percent level. This may be because enforcement of localism occurs in the lineup, which is the queue surfers wait in for their turn to surf a wave. When the current is calm, policing that break is much easier than when the current is roaring and waves are breaking haphazardly. The negative coefficient is consistent with an interpretation of paddling as a cost associated with enforcing property rights and can be interpreted as a 10 percent increase in paddling difficulty leading to a 4 percent decrease in localism. Alternatively, paddling difficulty could reduce localism because the vigor of the current may naturally cull the herd and reduce the need to enforce localism. The coefficients on dirtiness, paddling difficulty, and highway distance remain relatively similar across the various specifications.

Two immediate issues spring to the fore regarding this estimation. ${ }^{22}$ First, the OLS estimation assumes that the measures of localism are equally spaced (the difference between a localism measure of 3 and 4 is the same as the difference between a localism measure of 7 and 8). Given the subjective indexing of localism, this may be a weak assumption. To ensure that this result is not spurious, I estimate an ordered logit regression. The estimate for quality is still significant and consistent with the OLS estimate in column 1.

The other major issue of concern is that congestion is endogenous with lo-

${ }^{22}$ I performed additional robustness checks, including nonlinear specifications, county dummies, and maximum and minimum scores for ranged indexes. Results were consistent with those reported here and are available on request. 
Table 2

Changes in Localism

\begin{tabular}{|c|c|c|c|c|c|}
\hline & $\begin{array}{c}\text { OLS } \\
(1)\end{array}$ & $\begin{array}{c}\text { OLogit } \\
\text { (2) }\end{array}$ & $\begin{array}{l}\mathrm{IV}_{\mathrm{A}} \\
(3)\end{array}$ & $\begin{array}{l}\mathrm{IV}_{\mathrm{B}} \\
(4)\end{array}$ & $\begin{array}{c}\mathrm{IV}_{\mathrm{C}} \\
(5)\end{array}$ \\
\hline Quality & $.875^{\star}(.171)$ & $.713^{*}(.184)$ & $.759^{+}(.427)$ & $1.167^{\star}(.367)$ & $(.457)$ \\
\hline Congestion & $.290^{*}(.126)$ & $.287^{\star}(.132)$ & $.446 \quad(.492)$ & $-.103 \quad(.478)$ & $(.463)$ \\
\hline Dirty & $.144 \quad(.119)$ & $.127(.103)$ & $.153 \quad(.129)$ & $.122(.120)$ & $(.125)$ \\
\hline Work & $-.323^{+}(.168)$ & $-.287^{+}(.157)$ & $-.341^{+}(.186)$ & $-.274 \quad(.193)$ & $-.330^{+} \quad(.187)$ \\
\hline Hwydist & $.015 \quad(.026)$ & $.015 \quad(.025)$ & $.016 \quad(.027)$ & $.011 \quad(.027)$ & $(.023)$ \\
\hline Ability & & & & & $1.459^{*}(.493)$ \\
\hline Constant & $-1.57 \quad(1.093)$ & . & . $277(1.094)$ & $-1.421(1.193)$ & $-3.298^{\star}(1.091)$ \\
\hline$R^{2}$ & .50 & & .49 & .43 & .54 \\
\hline
\end{tabular}

Note. The dependent variable is Localism. Robust standard errors are in parentheses. For $\mathrm{IV}_{\mathrm{A}}$, the firststage $F$-statistic is approximately 12 . For $\mathrm{IV}_{\mathrm{B}}$ and $\mathrm{IV}_{\mathrm{C}}$, the first-stage $F$-statistic is approximately $10 . \mathrm{N}=$ 86 . OLS $=$ ordinary least squares; OLogit $=$ ordered logit; IV $=$ instrumental variable.

${ }^{+} p<.10$.

${ }^{*} p<.05$.

calism, which leads to erroneous estimates. ${ }^{23}$ While tests suggest only a weak endogeneity problem, an instrumental variable model is nonetheless estimated in column 3. Congestion is instrumented using county population densities, under the assumption that high population densities likely lead to larger crowds, all else equal, while having no direct impact on localism. The estimate on quality is slightly smaller and less significant than under OLS (an 11 percent increase in localism due to a 10 percent increase in quality), and congestion is no longer significant, which suggests that congestion has no exogenous effect on localism.

In column 4 , the robustness check is continued by adding Ability as an additional instrumental variable. If I interpret the recommended ability as a proxy for the difficulty of surfing at a particular site, then an increase in the difficulty of surfing may be culling the herd and reducing congestion, all else equal. This specification, $\mathrm{IV}_{\mathrm{B}}$, yields the largest quality estimates of any specification, with a 10 percent increase in quality leading to a 17 percent increase in localism.

On the other hand, it is possible that the recommended ability level of a break also tells us something about the locals associated with it. ${ }^{24}$ Recommended ability is included as an explanatory variable of localism in the final model, $\mathrm{IV}_{\mathrm{C}}$. Including ability decreases the coefficient on quality to a smaller and insignificant estimate of a 7 percent increase in localism for a 10 percent increase in quality. The coefficient on Ability is highly significant, with a 10 percent increase in recommended ability leading to a 10 percent increase in localism. However, a Pearson correlation of .605 (significant at the 1 percent level) suggests a high

${ }^{23}$ Excluding the congestion variable entirely leads to a highly significant quality coefficient of 1.07. In the instrumented regressions, the first-stage $F$-statistic is 10 or greater, which alleviates concerns of a weak instrument.

${ }^{24}$ Under a Tiebout sorting process, expert surfers might be expected to settle near expert breaks. If so, these better surfers might be better at excluding nonlocals, reducing the cost of exclusion. 
degree of collinearity, which makes identifying the effects of quality versus the effects of ability difficult.

\subsection{Implications}

What can we learn from the preceding estimation results? First, drawing from the analytical model, we see that localism is significantly and positively correlated with quality, which suggests that locals derive more benefit from increasing quality than do nonlocals. Locals recognize the benefits of high-quality waves and endogenously create strong property rights to capture them.

Second, the negative relationship between paddling difficulty and localism demonstrates the role that costs play in determining enforcement. While the coefficient on highway distance is insignificant, its consistent positive sign may indicate that more remote locations (far from urban centers) experience more localism. This is consistent with suggestions that when authorities look the other way, informal property rights tend to be stronger (Acheson and Brewer 2000). Intimidating nonlocals on a deserted stretch of the central coast may go unnoticed, while similar behavior along a busy urban beach in Orange County would draw far more attention from local authorities.

Finally, the correlation between exogenous quality and the strength of property rights suggests that studies looking to strong property rights as a determinant of resource quality need to account for this endogeneity. For example, Acheson (1988) contrasts the highly productive lobster grounds in the waters of the more vigorously defended islands of Maine with the less productive lobster grounds of the less defended mainland harbors to suggest that vigorous defense by island lobstermen has led to better fishing. The results presented in the present paper suggest there may be a plausible alternative whereby lobstermen recognize the higher quality fishing grounds near the islands and establish their informal property rights to protect them. There may be many reasons why the island fisheries would be more productive, independent of any institutional argument, such as oceanographic currents supplying more food or less runoff and pollution near the islands, or the underwater topography being more conducive, or any other number of factors. This is not to suggest that the vigorous defense of property rights by the island groups has had no influence on resource quality but rather to highlight a potential endogeneity concern. Most likely, there are feedbacks (potentially positive) between quality and property rights leading to the observed relationship between the vigorous island defense and productivity.

\subsection{Empirical Limitations}

A few limitations of the empirical study are worth mentioning. First, the crosssectional data provide snapshot, aggregate measures of quality, congestion, and localism, yet these variables change literally by the hour. With the proliferation of surf Web cams, measurement buoys, and geographic information system mappings of oceanographic contours, a dynamic study that captures the evo- 
lution of these variables may yield additional insight. Anecdotal evidence strongly suggests that localism can be particularly bad when the waves are extraordinarily good, especially at the start of the surf season. A panel data set would allow for identification within sites, as opposed to across sites, which could remove some confounding issues such as varying subcultures and local crime rates. ${ }^{25}$

Second, localism may take many different dimensions at different sites, and aggregating these dimensions into a simple index may hide interesting behavior. For example, it has been noted that locals confront nonlocal posers more aggressively, while giving humble nonlocals who can surf more latitude. This suggests that some localism behavior may be motivated by a desire not to see good waves wasted by bad surfers unable to ride the wave. Obviously, this type of behavior cannot be examined with aggregate data, but the behavior indicates that there may be an interesting public good component to surfing.

\section{Conclusions}

This paper expands on the property rights literature to consider the impact of exogenous resource quality on informal property rights when locals and nonlocals compete for resources. The simple analytical model finds that an increase in quality does not necessarily make locals better off. The indirect effects of increased congestion from nonlocals may overwhelm the direct benefits of increased quality, leaving locals worse off than they were before. Simple analytical examples show that if locals derive more benefit from quality in both absolute and marginal terms, property rights become stronger, and vice versa. Furthermore, if locals and nonlocals are homogenous, an increase in quality leaves locals no better or worse off and localism is unaffected.

I use surfing data from 86 breaks in central and southern California to estimate the impact of wave quality, cleanliness, paddling difficulty, and access on the strength of property rights. I find a robust, significant positive correlation between quality and localism, such that a 10 percent increase in quality leads to a 7-17 percent increase in the strength of property rights. I find a significant negative correlation between paddling difficulty and property rights: a 10 percent increase in difficulty leads to a 4 percent decrease in property rights, which is consistent with interpreting paddling difficulty as a cost of enforcing localism.

The empirical finding shows that quality plays a powerful role in determining the strength of informal property rights. For surfers, the gains from exclusion from valuable breaks outweigh the exclusionary cost, despite the additional costs of enforcing those informal rights. This is in line with theories on the endogenous formation of property rights, which suggest that users create property rights when the benefits outweigh the costs of exclusion. While the empirical study considers only one particular common-property resource, the similarities be-

${ }^{25}$ County population densities and distance variables were included to control for some of this variation. 
tween it and other common-property resources suggest that caution should be exercised in assigning causality of high resource quality to stronger property rights. Locals may be responding to the benefits of high-quality resources and endogenously creating stronger property rights to capture them.

Despite the presence of localism, many surf breaks still suffer from heavy congestion and overcrowding. The success of individual transferable quotas in fisheries and exclusive surf resorts, where individuals pay to surf uncongested waves, has led some to speculate about privatization of surf breaks-a proposition that leaves many surfers colder than a winter swell on the central coast.

\section{References}

Acheson, James M. 1988. The Lobster Gangs of Maine. Hanover, N.H.: University Press of New England.

Acheson, James M., and Jennifer Brewer. 2000. Capturing the Commons: Social Changes in the Territorial System of the Maine Lobster Industry. Paper presented at the eighth conference of the International Association for the Study of Common Property, Bloomington, Ind., May 31-June 4.

Borden, Mark. 2005. Who Owns This Wave? Sports Illustrated, April 18. http://vault .sportsillustrated.cnn.com/vault/article/magazine/MAG1103839/1/index.htm.

Carroll, Nick. 2005. California Underground. Surfing Magazine 41(5):80-103.

Coase, R. H. 1960. The Problem of Social Cost. Journal of Law and Economics 3:1-44.

Cole, Daniel. H. 2002. Pollution and Property: Comparing Ownership Institutions for Environmental Protection. Cambridge: Cambridge University Press.

Demsetz, Harold. 1967. Towards a Theory of Property Rights. American Economic Review (Papers and Proceedings) 57:347-57.

Ellickson, Robert C. 1986. Of Coase and Cattle: Dispute Resolution among Neighbors in Shasta County. Stanford Law Review 38:623-87.

Gordon, H. Scott. 1954. The Theory of a Common Property Resource: The Fishery. Journal of Political Economy 62:124-42.

Hardin, Garrett. 1968. The Tragedy of the Commons. Science 162:1243-8.

Heller, Greg. 2000. The Ranch. In Surfing A to Z: The Largest Surfing Encyclopedia. http: //www.surfline.com/surfing-a-to-z/the-ranch-history_927.

Libecap, Gary D. 1989. Contracting for Property Rights. Cambridge: Cambridge University Press.

Nazer, Daniel. 2004. The Tragicomedy of the Surfers' Commons. Deakin Law Review 9: 655-714.

Ostrom, Elinor. 1990. Governing the Commons. Cambridge: Cambridge University Press.

Rider, Robert. 1998. Hangin' Ten: The Common-Pool Resource Problem of Surfing. Public Choice 97:49-64.

Scott, Anthony. 1955. The Fishery: The Objectives of Sole Ownership. Journal of Political Economy 63:116-24.

Sydsaeter, Knut, Arne Strom, and Peter Berck. 1999. Economists' Mathematical Manual. 3d ed. Berlin: Springer.

Umbeck, John R. 1981. Might Makes Right: A Theory of the Foundation and Initial Distribution of Property Rights. Economic Inquiry 19:38-59. 